\title{
Experimental Research on Longitudinal Steel Bar Bond Properties in Modified Recycled Aggregate Concrete Beam-Column Interior Joint under Cyclic Loading
}

\author{
Jia-Li Fu, ${ }^{1,2}$ Bing-Kang Liu, ${ }^{1}$ and Jun-Wei $\mathrm{Ma}^{3}$ \\ ${ }^{1}$ School of Civil Engineering, Hefei University of Technology, Hefei 230009, China \\ ${ }^{2}$ School of Architecture and Civil Engineering, Anhui Polytechnic University, Wuhu 241000, China \\ ${ }^{3}$ School of Civil Engineering, Southeast University, Nanjing 210096, China \\ Correspondence should be addressed to Bing-Kang Liu; liubingkang@hfut.edu.cn
}

Received 9 December 2016; Accepted 15 March 2017; Published 3 May 2017

Academic Editor: Luigi Nicolais

Copyright ( 2017 Jia-Li Fu et al. This is an open access article distributed under the Creative Commons Attribution License, which permits unrestricted use, distribution, and reproduction in any medium, provided the original work is properly cited.

\begin{abstract}
Three recycled aggregate concrete (RAC) beam-column interior-joint specimens (including two modified recycled aggregate concrete interior joints with replacement of fly ash ratio of $15 \%$ ) were tested under cyclic loading in order to study the bond behavior of the longitudinal steel bar at RAC joint. The tests obtained load-strain hysteresis curves of longitudinal bars. The relative bond strength of longitudinal bar in characteristic stages was calculated. The test results indicated that the longitudinal steel bar in RAC joint is able to supply a stable bond stress both in the full crack stage and in the ultimate stage, meaning that the requirements of stress transferring and displacement coordinating between RAC and reinforcements can be satisfied. The larger the diameter of steel bar, the more serious the bond strength degradation. The RAC with fly ash can improve the interface compactness and bond strength of recycled aggregate in full crack stage. When beam-column interface of concrete compression zone reaches ultimate strain, the compressive stress of the longitudinal reinforcement cannot be exerted. The bond stress of the steel bar cannot realize the pull and compressive stress conversion in the length of the core area of the joint owing to the stress hysteresis of the compression rebars.
\end{abstract}

\section{Introduction}

As a new green construction material, recycled aggregate concrete has been of widespread concern in construction industry. It does not only solve the environment pollution caused by abandoned construction waste but also alleviate the ecological pressure caused by natural aggregate mining. As a new structure, RAC structure has been systematically researched in material properties and structural components by many scholars and obtained large amount of research achievements. Existing research of RAC mainly focuses on two points: properties of RAC materials and performances of RAC members. Compressive strength [1-4], tensile strength [5-7], elastic modulus [8,9], constitutive relationship [1012], and durability [13-16] of RAC materials have been widely investigated. Flexural and shear performance of RAC beams [17-20], compressive performance of RAC column [21-24], seismic performance of RAC beam-column joint [25-27], RAC shear wall [28], and RAC frame structure [29] have also been reported in previous papers. However, there is little deep research on the steel bar bond properties of RAC structure, most of which are achieved by drawing test [30-34]. Existing research on bond properties under cyclic load only focused on ordinary concrete structure but few pay attention to RAC structure [35].

Many of the earthquake damage and experimental tests on ordinary concrete structures have indicated that, under strong earthquakes or cyclic load, the bond stress between concrete and reinforcement steel bars will be decreased at the joint, leading to the decrease of the joint stiffness and loss of the joint capacity, and finally the steel bar's bond and anchor failure at the joint position usually caused the frame structural failure. From the above failure mode, it can be concluded that better bond and anchor properties are a 
necessary condition to ensure a better cowork between RAC and reinforced steel bars and steel bar bond properties are a key factor to ensure RAC structures have well seismic properties.

At present, the study of the bond behavior of steel bars in the RAC structure is mainly through the one-way pullout test, the unidirectional drawing bond behavior of steel bar is not applicable on seismic resistant structure, and steel bar-concrete bond behavior under cyclic load of ordinary concrete structures obtained was different from that of the RAC. In order to put the RAC structures into application in seismic areas, it is very necessary to carry out researches on steel bar bond properties of RAC joint under cyclic load. By experiments of three RAC beam-column interior joints under cyclic load, this paper studied the bond and slip properties of longitudinal steel bar crossing the RAC joint core area, and the research results can provide theory foundation for applying RAC structure in earthquake regions.

\section{Experiments Details}

2.1. Specimen Design. This experiment produced three fullsize RAC beam-column interior-joint specimens. Among the three specimens, specimens ZJ1 and ZJ2 used the modified RAC adding mineral fly ash and different longitudinal steel bar diameters in order to investigate the refection of bar diameter to bond strength; specimen ZJ3 used ordinary $\mathrm{RAC}$, and the reinforcements configuration is the same as that of ZJ1 and ZJ2, which is to investigate the bond properties differences between ordinary RAC and mineral fly ash modified RAC. Specimen size and reinforcements detail are shown in Figure 1.

2.2. RAC and Reinforcement Steels. Recycled aggregate is from building demolition wasted concrete, and the RAC production was according to the "Standard for Technical Requirements and Test Method of Sand and Crushed Stone (or Gravel) for Ordinary Concrete" (JGJ52). The tested basic properties of recycled aggregate are shown in Table 1. The RAC design strength grade is C30. The concrete production used ordinary river sand, city supplied water as the stirred water, and grade 42.5 Portland cement. The mixing proportion and RAC standard cube compressive strength are shown in Table 2, wherein specimens ZJ1 and ZJ2 used 15\% mineral fly ash to replace the same cement amount. The longitudinal steel bar grade is HRB400, and the tested steel bar mechanical properties are shown in Table 3.

2.3. Experimental Setup and Measuring System. The quasistatic loading method was adopted in the experiment. Specimens were loaded by MTS electrohydraulic loading system fixed on load-carrying frame and the loading setup is shown in Figure 2. The column designed of axis compression ratio is 0.25 . The axial force was applied by the hydraulic jack on top of the column, and a couple of cyclic load was applied on both ends of the specimen's beams by MTS electrohydraulic system after the axial force was loaded. The loading process was hybrid control of force and displacement. Before the
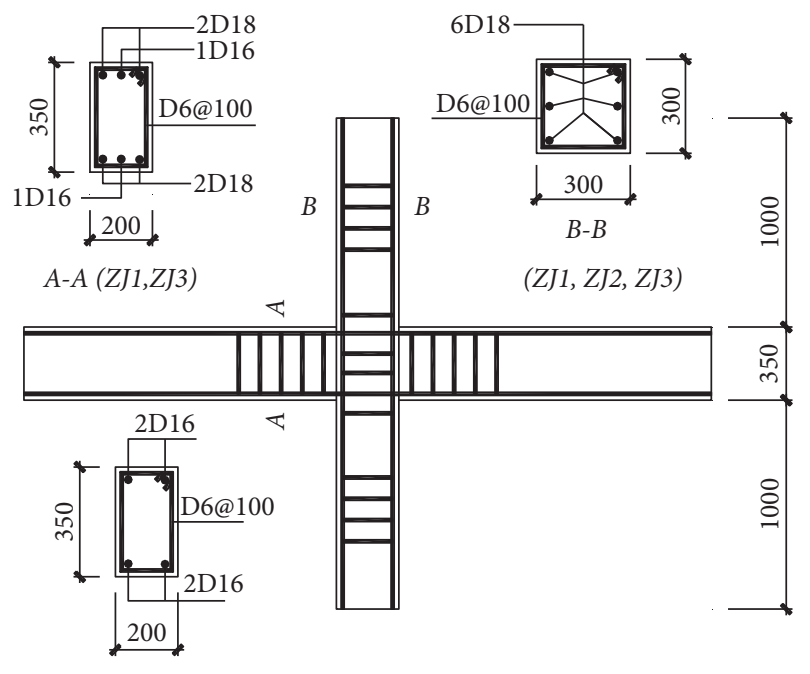

$(Z J 1, Z J 2, Z J 3)$

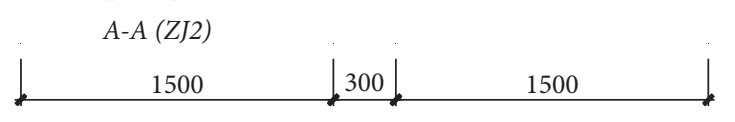

FIGURE 1: Specimens dimension and reinforcements.

yielding of the specimen occurred, the loading was controlled by force and applied once cycle in per loading level. After yielding of the specimen occurred, the loading was controlled by displacement of increasing by $10 \mathrm{~mm}$ from the yield displacement and applied three cycles in per loading level. In each loading level, the loading time interval remained the same until the specimen was damaged. The measurements of this experiment contained strains and displacements. All the strains and displacements data were collected and saved by JM3813 static strain test-analysis system. The measures of the data are as follows.

2.3.1. Strain Gauges. Stain gauges were embedded on longitudinal steel bar at the two ends of beam on both sides of joint. The strain gauges configuration and number on the reinforcements were shown in Figure 3. By measuring strain gauges value, the bond stress exchange situation of longitudinal steel bar crossing the joint core area can be determined. The strain distribution and the rotation angel of the beam end section can be determined by displacement meter arranging at the top and bottom of the beam on both sides of the column. Some strain gauges were set on the confinement stirrups at the joint core area, to collect the confinement stirrups' strain data.

2.3.2. Displacements. At the free end of beams, the MTS sensor can be used to measure the displacement. The MTS tested displacements were also the loading control parameter in the displacement controlled loading stage. At the joint core area, displacement meters were set to collect joint section deformation. Apart from that, two cross configured displacement gauges were also set at the joint core area to test the joint deformations, which can be used to calculate the joint shear deformation angle. 
TABLE 1: Basic performance indexes of the recycled aggregate.

\begin{tabular}{lcccc}
\hline Crash ratio (\%) & Water content ratio (\%) & Water absorption ratio (\%) & Apparent density $\left(\mathrm{kg} / \mathrm{m}^{3}\right)$ & Micropower ratio $(\%)$ \\
\hline 12 & 1.8 & 4.7 & 2627 & 3.3 \\
\hline
\end{tabular}

TABLE 2: RAC mix properties and compressive strength.

\begin{tabular}{lccc}
\hline Specimen & Recycled aggregate ration (\%) & $\begin{array}{c}\text { RAC mixing proportion } \\
\text { Cement : fly ash : sand : coarse } \\
\text { aggregate }: \text { water }\end{array}$ & Cube compressive strength (MPa) \\
\hline ZJ1, ZJ2 & 100 & $394: 70: 550: 1169: 226$ & 30.2 \\
ZJ3 & 100 & $464: 0: 550: 1169: 226$ & 32.2 \\
\hline
\end{tabular}

TABLE 3: Measured mechanical properties of reinforcements.

\begin{tabular}{lccccc}
\hline Bar diameter $(\mathrm{mm})$ & Steel type & $\begin{array}{c}\text { Yield strength } \\
\left(f_{p y} / \mathrm{MPa}\right)\end{array}$ & $\begin{array}{c}\text { Ultimate strength } \\
\left(f_{p t} / \mathrm{MPa}\right)\end{array}$ & $\begin{array}{c}\text { Elastic modulus } \\
(E / \mathrm{MPa})\end{array}$ & Elongation $(\%)$ \\
\hline D16 & Deformed bar & 550.0 & 664.3 & $2.0 \times 10^{5}$ & $20.0 \%$ \\
D18 & Deformed bar & 487.5 & 625.1 & $2.0 \times 10^{5}$ & $22.5 \%$ \\
\hline
\end{tabular}

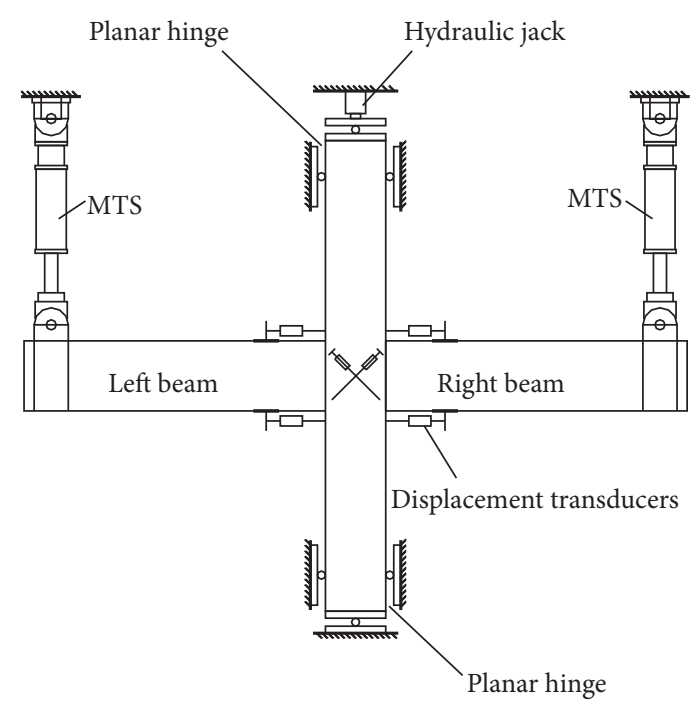

FIGURE 2: Test setup.

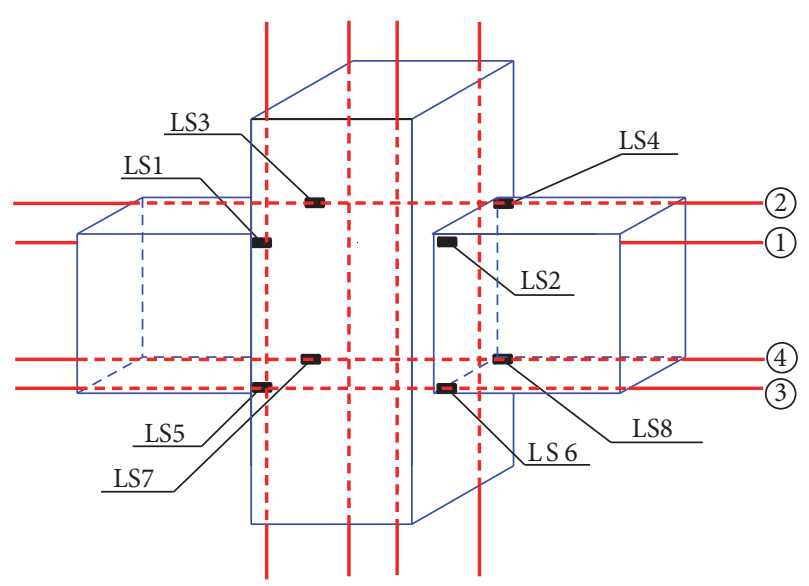

FIgURE 3: Configuration of strain gauges.

\section{Experimental Phenomenon and Analysis}

3.1. Experimental Phenomenon. The shear failure happened on joints core area of all the three specimens. The failure process can be divided into the initial crack stage, the full crack stage, the ultimate stage, and the failure stage, and the damage and failure mode is familiar to that of ordinary concrete frame joint. In the process of the joint shear failure, a bending damage occurred at the joint connected beam end section, in which the yielding of the longitudinal steel bar crossing beam end section and the sectional compression concrete reached its compressive strength. In the failure stage, there was no longitudinal crack along the steel bar and splitting failure on concrete covers, indicating that the surface of longitudinal reinforcement keeps better bonding performance with concrete. The joints core area cracks and damage of all the three specimens in the initial crack stages, the full crack, the ultimate stage, and the failure stage are shown in Figure 4 .

3.2. Load-Strain Hysteresis Curve. Bearing two antisymmetrical loads on both free ends of beams, the same longitudinal steel bar crossing joint area was tensioned at one joint side while being compressed at the other joint side; the successive tension and compression transfer of longitudinal steel bar mainly depend on the bond force on the surface of longitudinal steel bar through joint core area range. During the experimental test, load-strain hysteresis curves of longitudinal steel bar at the joint beam end section were recorded, and all the load-strain hysteresis curves are shown in Figures 5, 6, and 7. Take the load-strain hysteresis curves of steel bars in specimen ZJ1 (Figure 5) as an example to illustrate its characteristics as follows:

(1) Strains from gauges LS1 and LS3 of specimen ZJ1 have a linear relationship with load $P$ even when load $P$ varies from positive to negative. Even in the full 


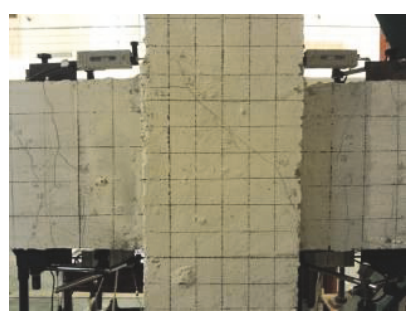

(a) ZJ1 in initial crack stage

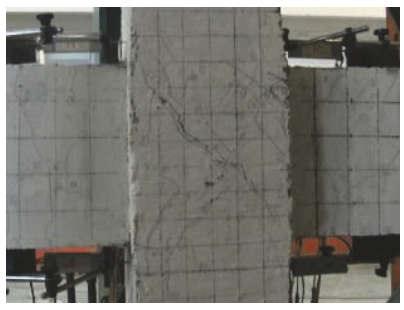

(e) ZJ2 in initial crack stage

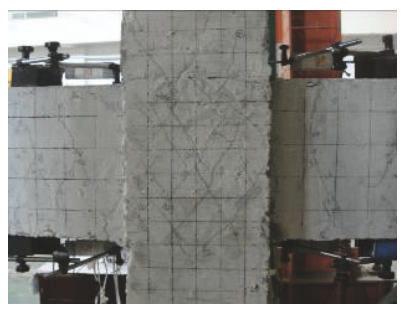

(i) ZJ3 in initial crack stage

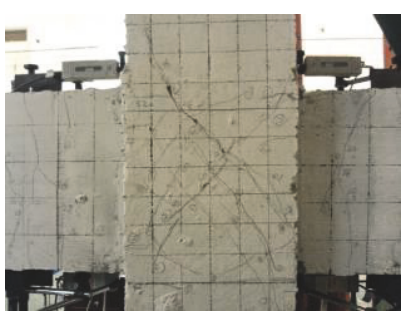

(b) ZJ1 in full crack stage

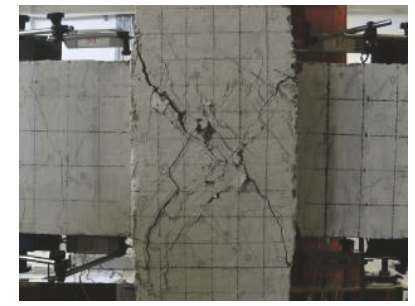

(f) ZJ2 in full crack stage

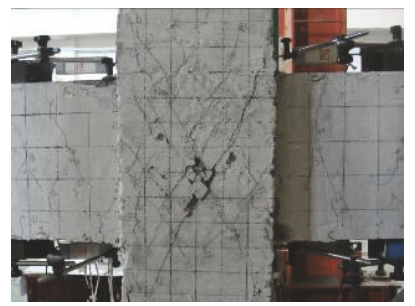

(j) ZJ3 in full crack stage

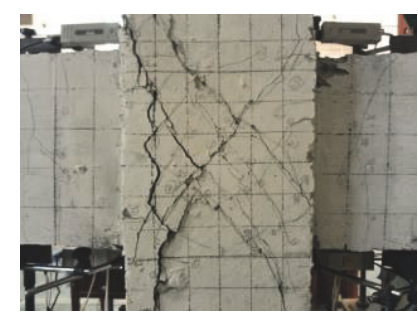

(c) ZJ1 in ultimate stage

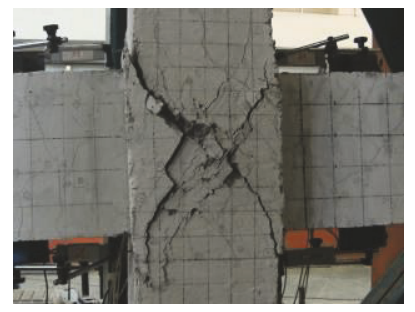

(g) ZJ2 in ultimate stage

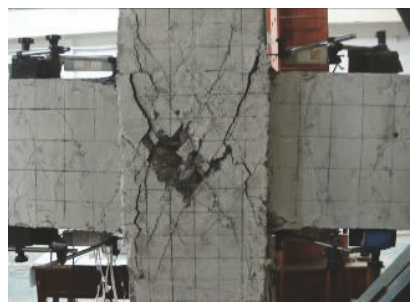

(k) ZJ3 in ultimate stage

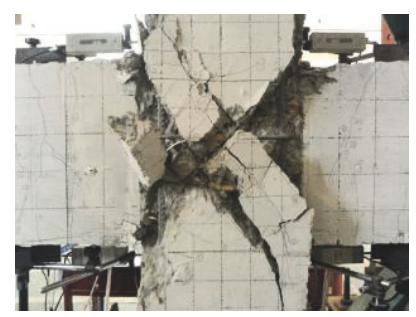

(d) ZJ1 in failure stage

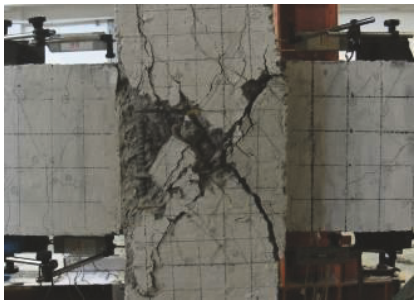

(h) ZJ2 in failure stage

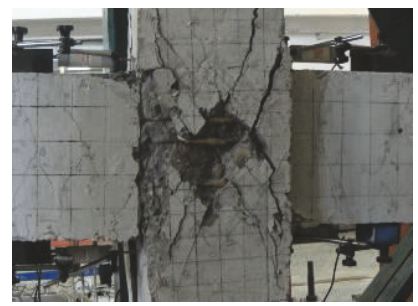

(l) ZJ3 in failure stage

FIGURE 4: Damaged state of specimens in joints core area.

crack loading stage and the ultimate loading stage, the strains remain a stable relationship with load $P$, indicating no bond stress decrease.

(2) Strains from gauges LS2, LS4, LS5, and LS7 of specimen ZJ1 have a linear relationship with load $P$ in the early positive-negative loading stage. When the loading process goes into the full crack stage, tension strain occurred on steel bar in compressive area, which indicates that the bond force is not enough to ensure the successive tension-compression transfer of longitudinal steel bar in joint core area. This also indicates that interface failure and slip occurred on the steel bar-RAC surface. With the loading continuing, larger tension stress will occurred on compressive steel bars and the bond stress decreasing will be more serious.

(3) Sudden changes in tensile stress of longitudinal bars appear among the strains from gauges LS6 and LS8 of specimen ZJ1. This may be because a certain internal concrete part was damaged, leading to bond stress failure in one compressive loading process, and when the load transferred into tension load, a sudden slip occurred on longitudinal steel bar.

3.3. Strain Distribution in Beam Joint Section. From the displacement meters at the top and button position of joint's beam section, the average tension strain and compression strain within a $250 \mathrm{~mm}$ distance were obtained. According to the rule that the sectional strain satisfied the plate section assumption, the strain distribution of the joint connected beam section can be obtained and Figure 8 showed the joint connected beam sectional strain distribution of ZJ1.

In the test, two asymmetric forces of same value were kept applied on the free end of joint connected two beams. When loading into the failure stage, with the tension longitudinal steel bar yielding, the compression strain of the concrete at the sectional compression edge reached its failure limit and the accumulated damage of compression concrete emerged which finally resulted in a flexural failure at the joint connected beam end section. The section flexural failure symbols are usually the yield of longitudinal steel bars and the concrete reaching it ultimate compressive strength and the flexural capacity is determined by those symbols. Normally, the ultimate compressive strain value for ordinary concrete is $\varepsilon_{\mathrm{cu}}=0.0033$, while, for RAC, the ultimate compressive strain value is slightly higher. Considering the concrete compression ultimate strain improvement from confinement steel at the beam end, when the compressive strain value $\varepsilon_{\mathrm{cu}}$ reached from 0.006 to 0.007 , the concrete began to compress damage, so the $\varepsilon_{\mathrm{cu}}$ value for RAC can be assumed to be 2 times of the ordinary concrete value. Take yield strength $f_{y}=487.5 \mathrm{~N} / \mathrm{mm}^{2}$, elastic modulus $E_{s}=2.0 \times 105 \mathrm{~N} / \mathrm{mm}^{2}$, 


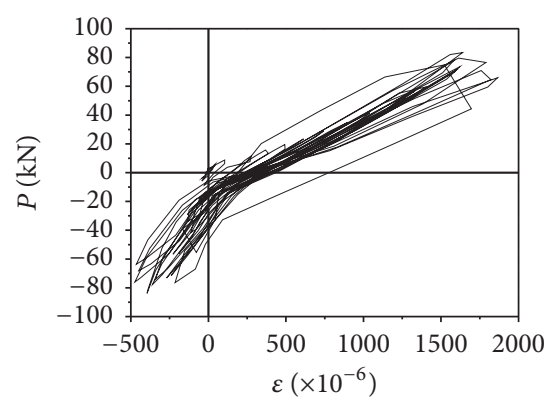

(a) LS1

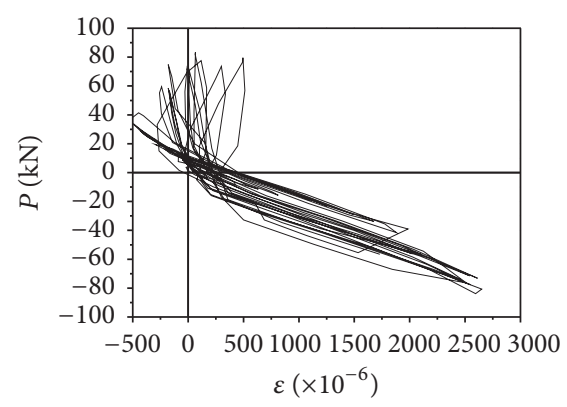

(d) LS4

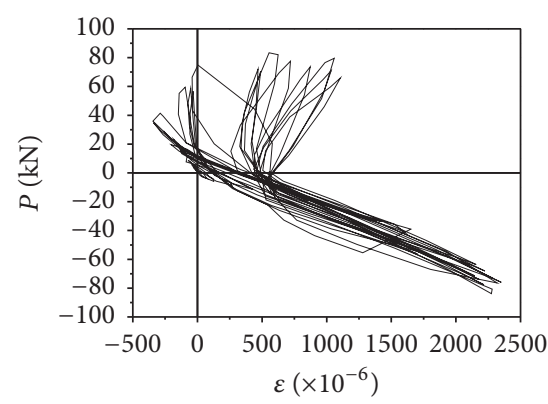

(b) LS2

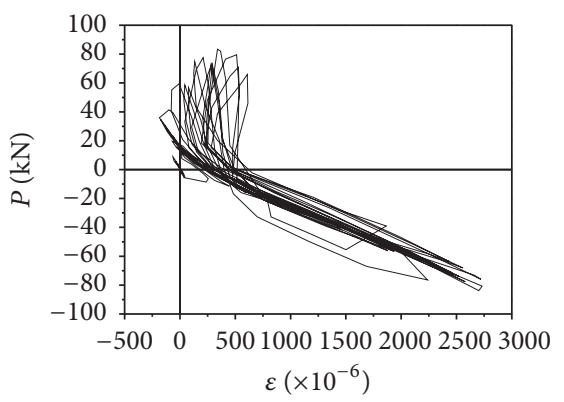

(e) LS5

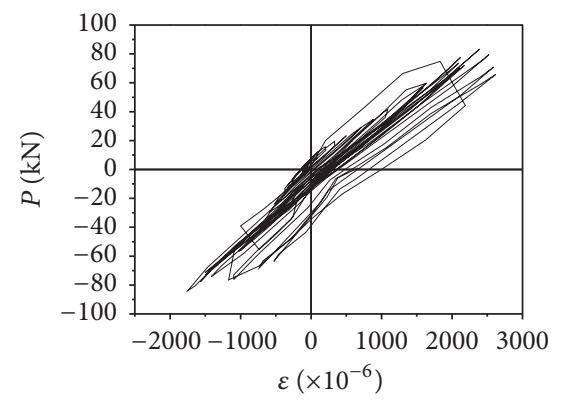

(c) LS3

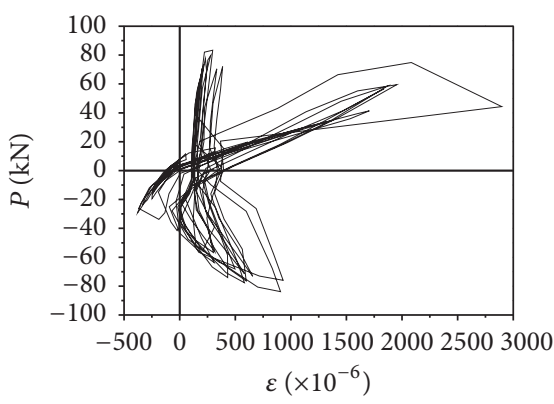

(f) LS6

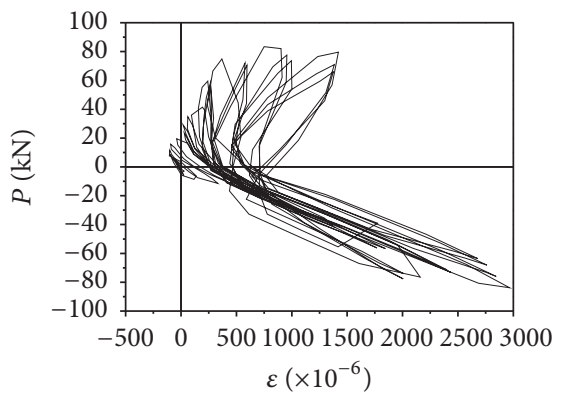

(g) LS7

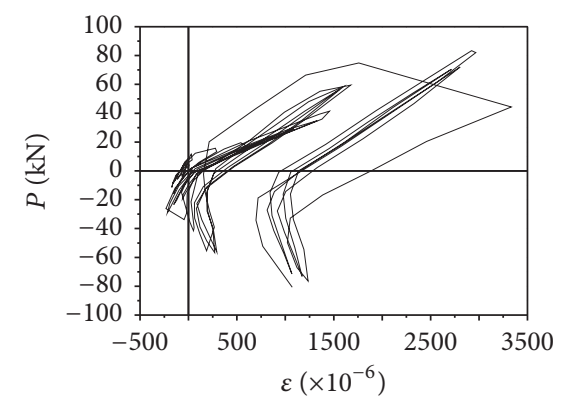

(h) LS8

FIGURE 5: Load-strain hysteresis curve of specimen ZJ1 longitudinal steel bar.

and yield strain $\varepsilon_{s}=0.00244$ for D18 longitudinal steel bars. Take yield strength $f_{y}=550.0 \mathrm{~N} / \mathrm{mm}^{2}$ and yield strain $\varepsilon_{s}=$ 0.00275 for D16 longitudinal steel bars.

Both the yield strains of D18 and D16 were less than the ultimate compressive strain of concrete, which means theoretically that the longitudinal steel bars yield first before the concrete damage. But the experimental results indicated that the actual compressive strain of longitudinal steel bar in compressive area was smaller than the corresponding sectional compressive strain value, which means that the longitudinal reinforcement cannot completely work in compression area.

The compression longitudinal steel bar strain was not synchronized with the concrete compression strain and a compression stress hysteresis performance existed. The reason that the compression stress hysteresis performance happened is as follows.

Different degrees of failures and cracks exist at the interfacial transition area between new and old mortar in RAC aggregate, causing a lower bond strength and weaker mechanical bite strength, which lead to insufficient bond force between concrete and steel bar. Finally, the tension and compression stress on one longitudinal bar cannot be transformed in the length of the reinforcement crossing the core area of the joint.

\section{Bonding Mechanism under Cyclic Loading}

4.1. Bonding Mechanism under Unidirectional Load. Bond strength between deformed steel bar and concrete depends on three parts including cementation force, friction force, and mechanical bite force. Under unidirectional load, the cementation force starts to work first in initial loading stage. With load increasing, cementation destroyed and a relative slip occurs between steel and concrete. At the same time, the oblique ribs on steel bar began to transmit pressure on concrete and generate cone wedging action, constituting slipping resist force working together with frictional force.

Decompose the oblique rib transmitted force into the transverse and longitudinal component forces shown in 


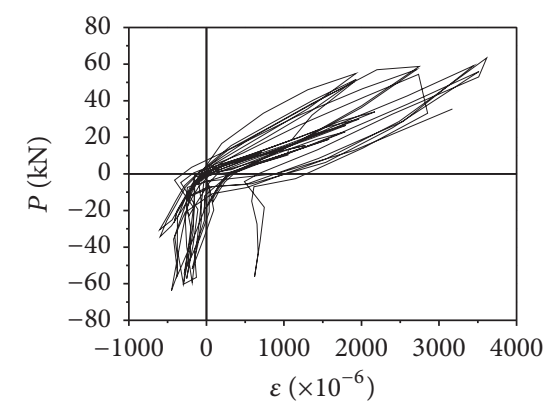

(a) LS1

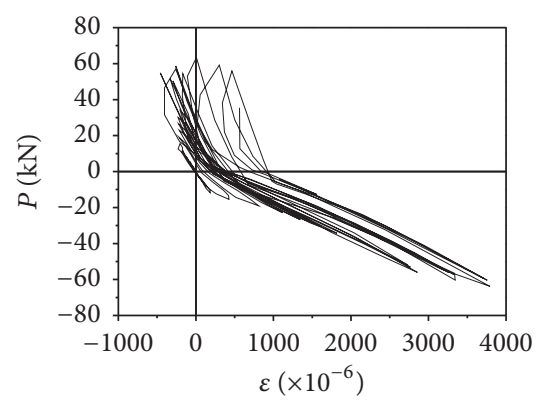

(d) LS4

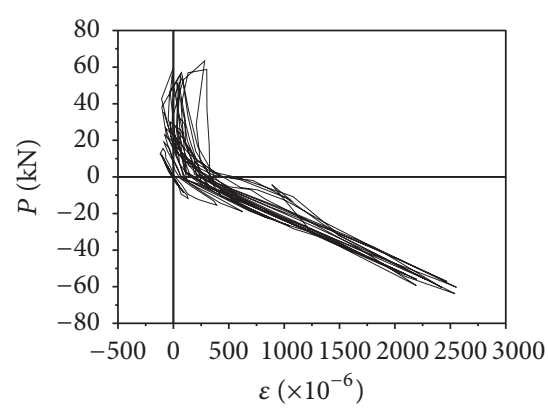

(b) LS2

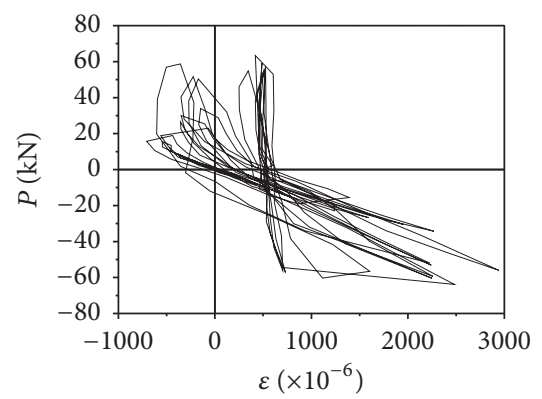

(e) LS5

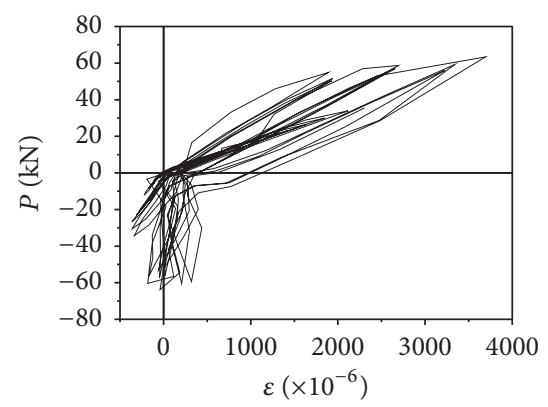

(c) LS3

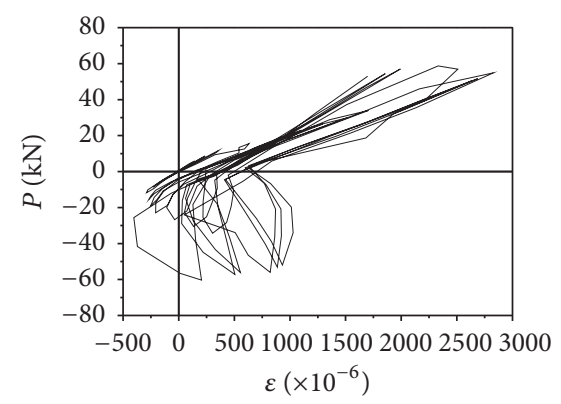

(f) LS6

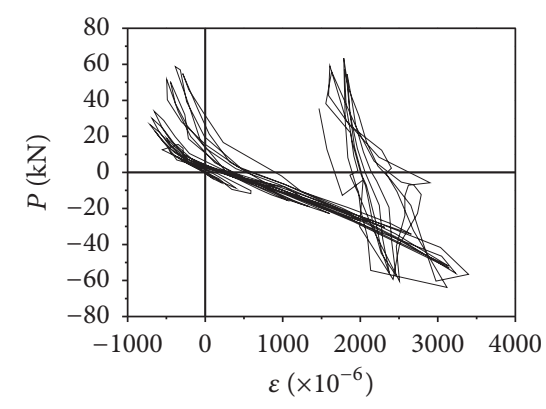

(g) LS7

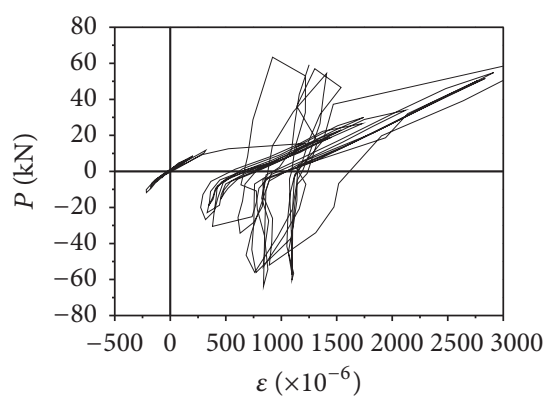

(h) LS8

FIGURE 6: Load-strain hysteresis curve of specimen ZJ2 longitudinal steel bar.

Figure 9(a). The transverse component force causes a ring tensile stress $\sigma_{\theta}$ on concrete around steel bar and synchronously the longitudinal component force causes a longitudinal tensile stress $\sigma_{z}$ on concrete. The combination of these two forces makes concrete in a complex threedimensional stress state. The ring tensile stress $\sigma_{\theta}$ causes internal radial cracks, and usually the bond stress, when the concrete protective layer cracks, was taken as a critical state of bond strength determination [36].

4.2. Bonding Mechanism under Cyclic Load. The cyclic load leads to an exchanging bidirectional stress on the joint steel bars and the bond properties between steel and concrete will be reduced dramatically compared to that under unidirectional load. As the cyclic times increase, the bond stress keeps decreasing and finally stabilizes to a balance. The load-bond strength curves under cyclic loading showed obvious hysteretic characteristics. In the positive loading stage, one side of the transverse steel bar ribs presses and leads irreversible deformation on concrete, while cracks and gaps exist on the other transverse ribs side caused by tension stress. When converting into the negative loading stage, the steel bar ribs slip after steel ribs-concrete surface friction is overcome, and, with the negative load increasing, the steel ribs begin to press the other concrete side. In this positive-negative load conversion process, the repeated loads on longitudinal steel bars do not only lead to a reduction of friction and mechanical bite action but also cause the "boundary layer" concrete surrounding steel bar to be damaged, resulting in bond properties deterioration (Figure 9(b)). At the same time, the cyclic slips exist in both loading directions, so that the friction and mechanical bite action between steel ribs and the concrete aggregate will be further reduced compared to that under unidirectional load.

The longitudinal bar on both sides of joint is subjected to the alternating action of tension and pressure under cyclic loading; with the increase of the number of cycles, the bond stress decreases and finally tends to be stable. The bond behavior between steel bar and concrete is obvious degradation compared to that one under unidirectional load. The 


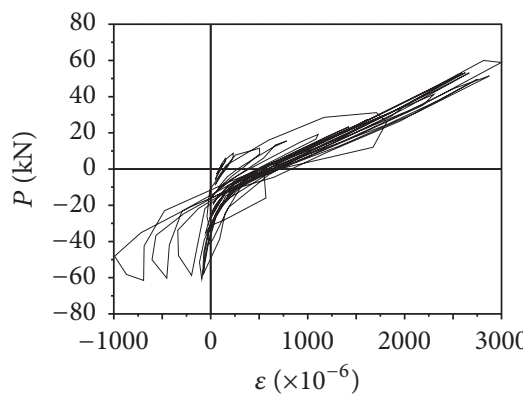

(a) LS1

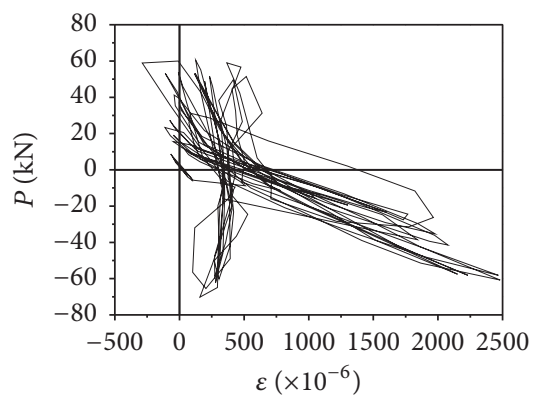

(d) LS4

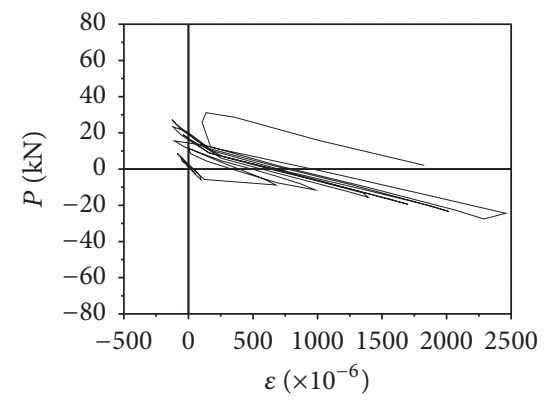

(b) LS2

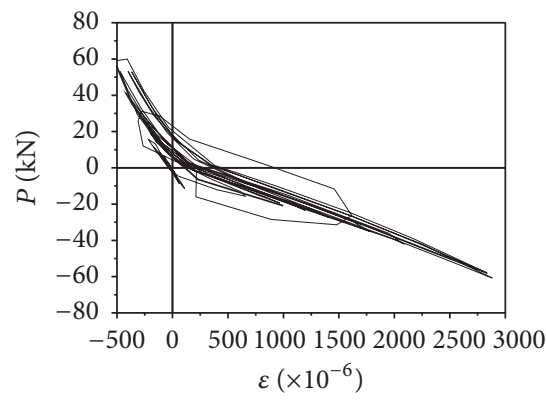

(e) LS5

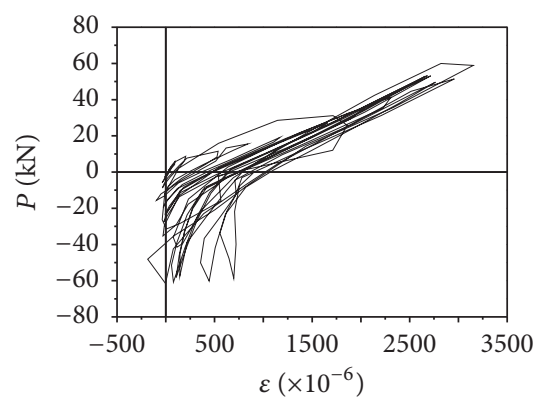

(c) LS3

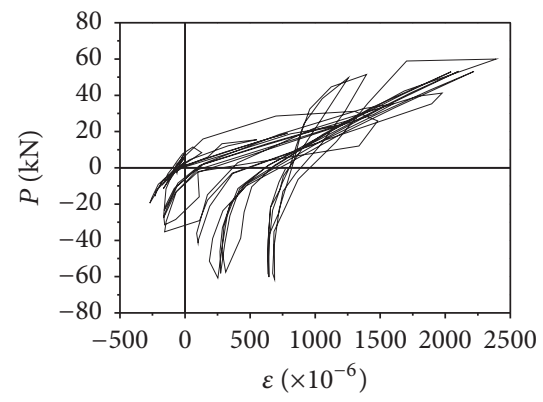

(f) LS6

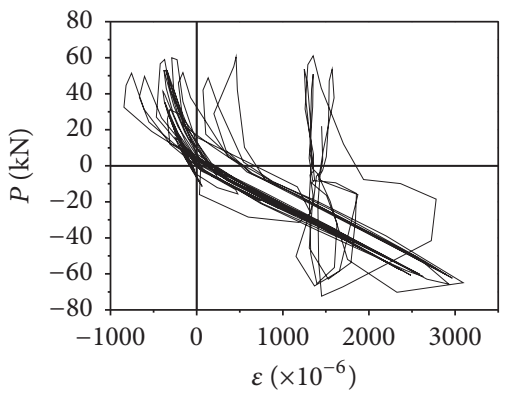

(g) LS7

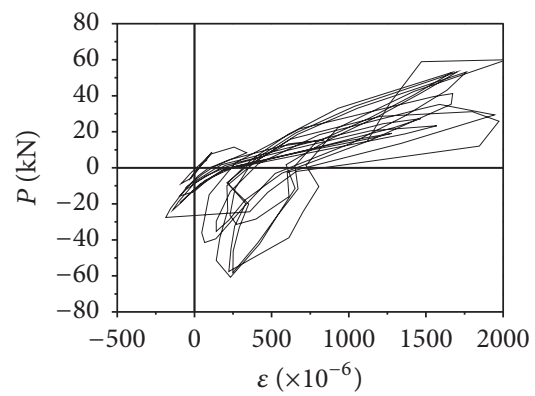

(h) LS8

FIGURE 7: Load-strain hysteresis curve of specimen ZJ3 longitudinal steel bar.

bond stress degradation degree relates to the loading process, the cyclic times, the lateral confinement effect, and some other factors. In the several early loading cycles, the average bond stress was low, and the cementing force and friction force proportion was large in the bond stress components. In the full crack loading stage, the transverse steel ribs were compressed and the mechanical bite action worked. In the ultimate loading stage, the "boundary layer" concrete surrounding steel bars was damaged, and the bonding slips happened and caused the steel bond stress to decrease. In the failure loading stage, significant steel bar bond slip happened on and the bond stress decreased rapidly. As a very strong lateral confinement was configured in the joint core area, no slip damage or steel bar pull out damage appeared. The experimental results indicate that more cyclic loading times or a larger controlled load (or controlled displacement) is related to more serious damage on the steel bar "boundary layer" concrete, and smaller friction and mechanical bite force along steel bar, and higher bond strength reduction.

\section{Bond Stress}

5.1. Load-Bond Stress Hysteresis Curve. The bond force magnitude can be measured by the variation of stress in steel bar [36]. The average bond stress in longitudinal steel bar can be calculated from the strain difference of two measure points on same longitudinal steel bar. The average bond stress between the two measure points can be calculated by the following formula:

$$
\tau=\frac{E_{s}\left(\varepsilon_{2}-\varepsilon_{1}\right) d}{4 l}
$$

where $l$ is the distance of two measure points, taken $300 \mathrm{~mm}$ in this experiment. $d$ is the measured steel bar diameter. $E_{s}$ is the elastic modulus of steel bar. $\varepsilon_{1}, \varepsilon_{2}$ are the strains of measured points, considering the yield strength of steel and strain gauge working range, taking 2750 as the value of $\varepsilon_{1}$ and $\varepsilon_{2}$ when they are beyond 2750 for the D16 steel bar and taking 


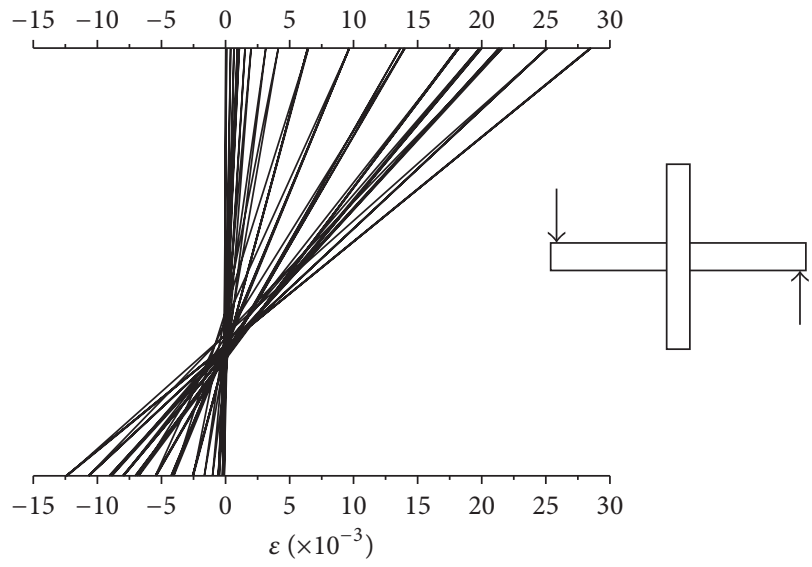

(a) Left beam on positive loading

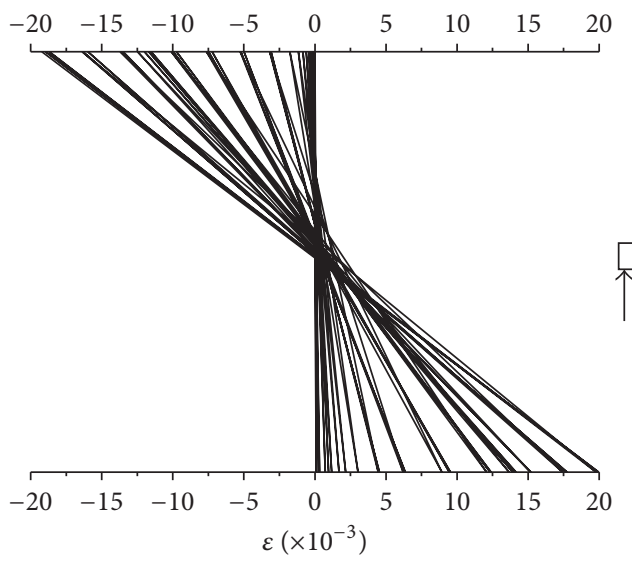

(c) Left beam on negative loading

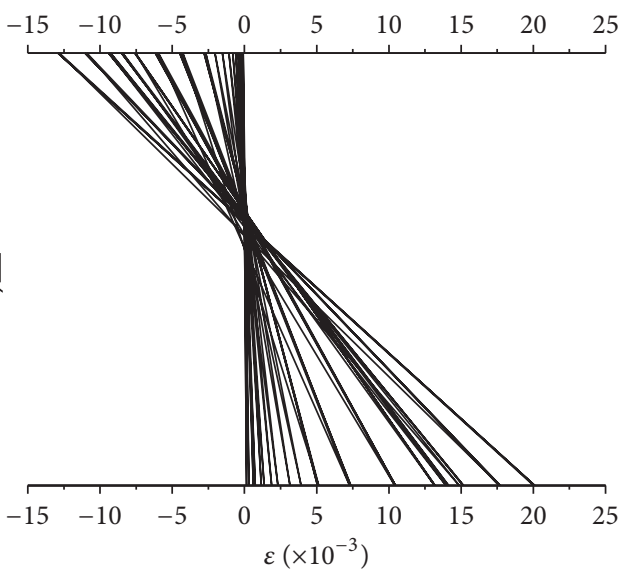

(b) Right beam on negative loading

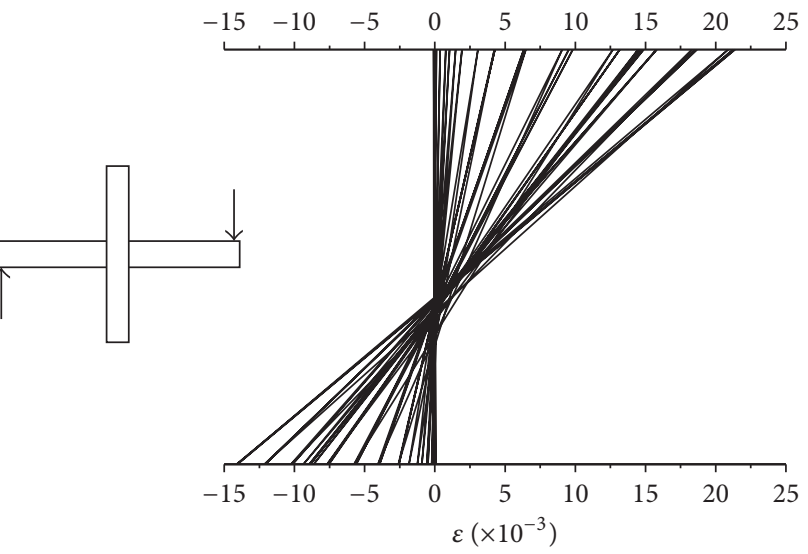

(d) Right beam on positive loading

FIGURE 8: Beam section strain distribution on two sides of column of specimen ZJ1.

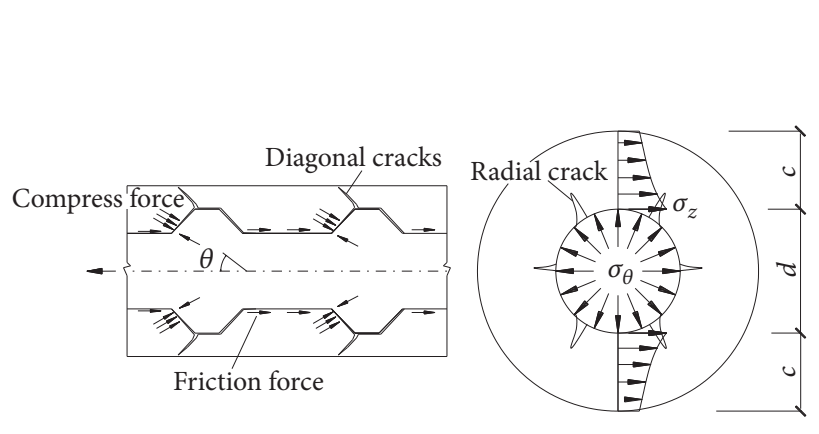

(a) Bonding mechanism under unidirectional load

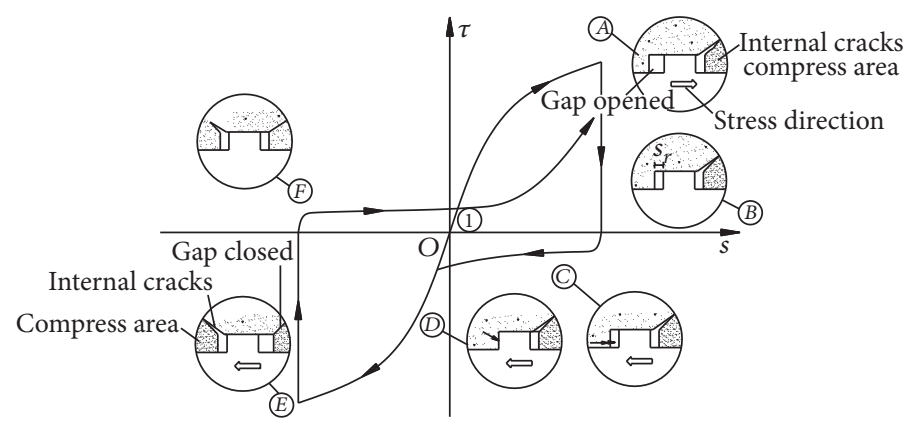

(b) Bonding mechanism under cyclic load

FIGURE 9: Bonding mechanism of longitudinal steel bar.

2440 as the value of $\varepsilon_{1}, \varepsilon_{2}$ when they are beyond 2440 for the D18 steel bar.

Strain gauges were set on all of the four longitudinal steel bars on the two sides of the joint at beam ends. The strain gauges and longitudinal steel bars relationship are as follows: gauges LS1 and LS2 to steel bar No. 1, gauges LS3 and LS4 to steel bar No. 2, gauges LS5 and LS6 to steel bar No. 3, and gauges LS7 and LS8 to steel bar No. 1.
Taking strains of two gauge measure positions on the same longitudinal steel bar and same loading cycle into formula (1), the corresponding average bond stress can be obtained. Taking ZJ1, for example, taking strain data in loadstrain hysteresis curves shown in Figures 5(a) and 5(b) into formula (1) synchronous overlap, and afterward adding data obtained from formula (1) into the curves, the average bond stress data and the load-bond stress hysteresis curves of 


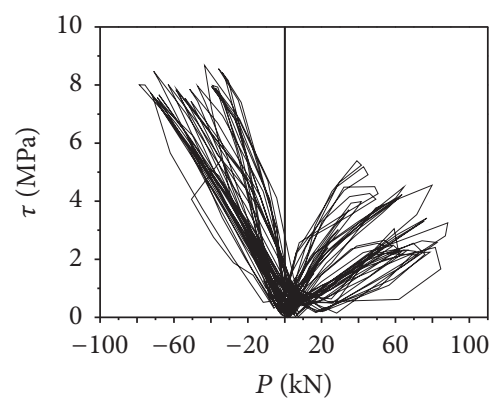

(a) Steel bar No. 1 in ZJ1

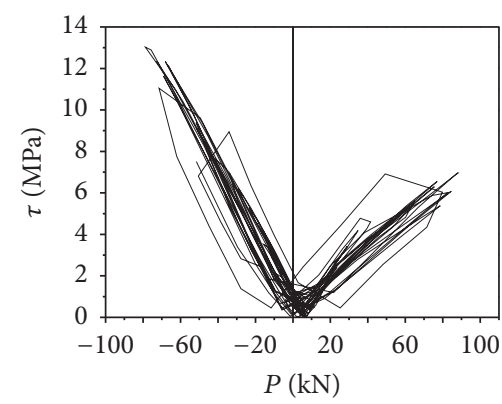

(b) Steel bar No. 2 in ZJ1

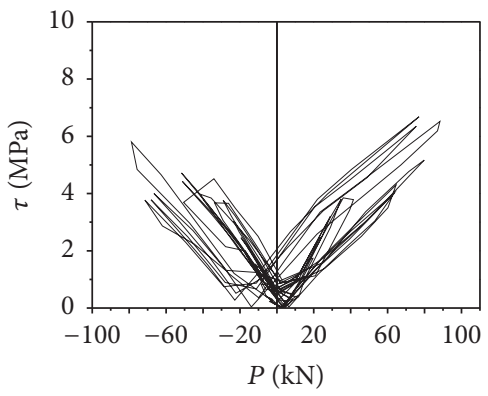

(d) Steel bar No. 4 in ZJ1

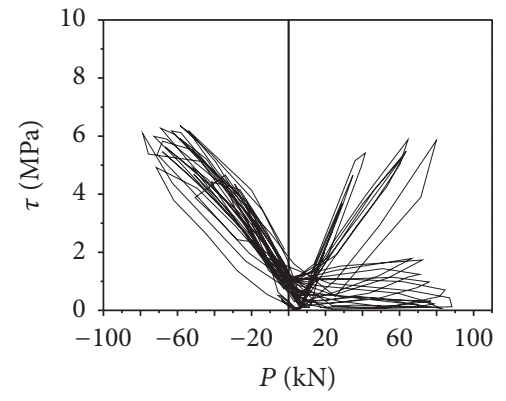

(c) Steel bar No. 3 in ZJ1

FIGURE 10: Load-bond stress hysteresis curve of tested longitudinal steel bars in ZJ1 specimen.

longitudinal steel bar can be obtained, shown in Figure 10(a). By the same way, the average bond stress hysteresis curve of all the tested longitudinal steel bars in specimens ZJ1, ZJ2, and ZJ3 can be obtained.

Curves in Figure 10 show the load-bond stress hysteresis curve of steel bars in specimen ZJ1. The four curves indicated the following:

(1) In the initial loading stage, the average bond stress is very low, and the bond stress distributions in positive loading and negative loading are symmetrical.

(2) In the full crack stage, the longitudinal steel bars at the compression area of beam end section show tension stress, indicating that the bond stress began to decrease. The positive and negative load-bond stress curves of most specimens are asymmetric, but all specimens maintain relative stable bond strength.

(3) Continue loading into the ultimate stage. After the bond stress reached its peak value, the increasing degree in the load-bond stress curves begins to decrease and the average bond stress begins to reduce which means that slips occur on longitudinal steel bars.

(4) In the failure stage, bond slips happen on part of the longitudinal steel bars and the bond stress of those steel bars decreases rapidly.

5.2. Average Bond Stress. In order to quantitatively study the development and failure process of bond stress on longitudinal steel bar in the three specimens, the corresponding average bond stresses of longitudinal steel bars in the full crack stage, the ultimate stage, and the failure stage are shown, respectively, in Table 4, concluded as follows:

(1) The bond stresses on longitudinal steel bar in the full crack stage and the ultimate stage are relatively stable. The average bond strength ranges from 6.512 to $7.439 \mathrm{MPa}$, and the relative bond strength ratio ranges from 0.208 to 0.246 .

(2) In the failure stage, the bond strength decreases rapidly. The average bond strength ranges from 3.723 to $4.505 \mathrm{MPa}$, and the relative bond strength ratio ranges from 0.116 to 0.150 .

Table 5 shows the statistic results of longitudinal steel bar bond stress at each stage obtained from experimental results shown in Table 4. For the sake of intuitive comparison, histograms are shown in Figure 11, which shows the relative bond stress of different steel bar diameters in common and modified RAC. And, from Figure 11, the following conclusions can be obtained:

(1) For the modified RAC specimens ZJ1 and ZJ2, the relative bond strength of the D18 longitudinal steel bar in the full crack stage is $96.3 \%$ of the D16 steel bar relative bond strength when other conditions remain same. In the failure stage, the relative bond strength ratio of the two specimens is $87.8 \%$.

(2) When the steel bar diameter is larger, the loss of bond strength is more serious. This is similar with the effect of steel bar diameter to bond strength in common concrete. This is also the reason why "Code for Seismic Design of Buildings (GB 50011)" limits the 
TABLE 4: Bond stress on longitudinal steel bar crossing joint in each of the loading stages.

\begin{tabular}{|c|c|c|c|c|c|c|c|c|}
\hline \multirow{2}{*}{ Specimen } & \multirow{2}{*}{$\begin{array}{c}\text { Steel bar number and } \\
\text { diameter }\end{array}$} & \multirow{2}{*}{ Loading direction } & \multicolumn{2}{|c|}{ Full-section crack stage } & \multicolumn{2}{|c|}{ Ultimate stage } & \multicolumn{2}{|c|}{ Failure stage } \\
\hline & & & $\tau_{y} / \mathrm{MPa}$ & $\tau_{y} / f_{\mathrm{cu}}$ & $\tau_{u} / \mathrm{MPa}$ & $\tau_{u} / f_{\mathrm{cu}}$ & $\tau_{p} / \mathrm{MPa}$ & $\tau_{p} / f_{\mathrm{cu}}$ \\
\hline \multirow{8}{*}{ ZJ-1 } & \multirow{2}{*}{ No. 1 D18 } & Positive & 4.491 & 0.149 & 3.255 & 0.108 & 2.148 & 0.071 \\
\hline & & Negative & 8.066 & 0.267 & 8.510 & 0.282 & 5.839 & 0.199 \\
\hline & \multirow{2}{*}{ No. 2 D18 } & Positive & 6.104 & 0.202 & 6.978 & 0.231 & 5.786 & 0.192 \\
\hline & & Negative & 12.387 & 0.410 & 13.029 & 0.431 & 8.232 & 0.273 \\
\hline & \multirow{2}{*}{ No. 3 D18 } & Positive & 5.874 & 0.195 & 1.734 & 0.057 & 0.126 & 0.004 \\
\hline & & Negative & 7.891 & 0.261 & 8.087 & 0.268 & 5.931 & 0.196 \\
\hline & \multirow{2}{*}{ No. 4 D18 } & Positive & 6.299 & 0.206 & 6.519 & 0.216 & 4.102 & 0.136 \\
\hline & & Negative & 4.719 & 0.156 & 3.980 & 0.132 & 3.872 & 0.128 \\
\hline \multirow{8}{*}{$\mathrm{ZJ}-2$} & \multirow{2}{*}{ No. 1 D16 } & Positive & 6.968 & 0.231 & 7.210 & 0.239 & 4.983 & 0.165 \\
\hline & & Negative & 6.932 & 0.230 & 7.220 & 0.239 & 4.532 & 0.150 \\
\hline & \multirow{2}{*}{ No. 2 D16 } & Positive & 7.909 & 0.262 & 8.646 & 0.286 & 4.565 & 0.151 \\
\hline & & Negative & 8.149 & 0.270 & 9.342 & 0.309 & 6.235 & 0.206 \\
\hline & \multirow{2}{*}{ No. 3 D16 } & Positive & 7.751 & 0.257 & 7.506 & 0.249 & 3.230 & 0.107 \\
\hline & & Negative & 5.208 & 0.172 & 6.010 & 0.199 & 1.342 & 0.044 \\
\hline & \multirow{2}{*}{ No. 4 D16 } & Positive & 8.472 & 0.281 & 8.735 & 0.289 & 2.987 & 0.099 \\
\hline & & Negative & 6.554 & 0.217 & 4.843 & 0.160 & 3.373 & 0.112 \\
\hline \multirow{8}{*}{ ZJ-3 } & \multirow{2}{*}{ No. 1 D18 } & Positive & 8.004 & 0.249 & 9.073 & 0.282 & 7.014 & 0.218 \\
\hline & & Negative & 3.101 & 0.096 & 1.776 & 0.055 & 0.538 & 0.017 \\
\hline & \multirow{2}{*}{ No. 2 D18 } & Positive & 8.478 & 0.263 & 10.224 & 0.318 & 7.642 & 0.237 \\
\hline & & Negative & 6.206 & 0.193 & 7.345 & 0.228 & 1.029 & 0.032 \\
\hline & \multirow{2}{*}{ No. 3 D18 } & Positive & 8.085 & 0.251 & 8.471 & 0.263 & 4.081 & 0.127 \\
\hline & & Negative & 7.893 & 0.245 & 7.935 & 0.246 & 2.022 & 0.063 \\
\hline & \multirow{2}{*}{ No. 4 D18 } & Positive & 6.420 & 0.199 & 1.482 & 0.046 & 0.654 & 0.020 \\
\hline & & Negative & 6.759 & 0.210 & 8.934 & 0.277 & 6.800 & 0.211 \\
\hline
\end{tabular}

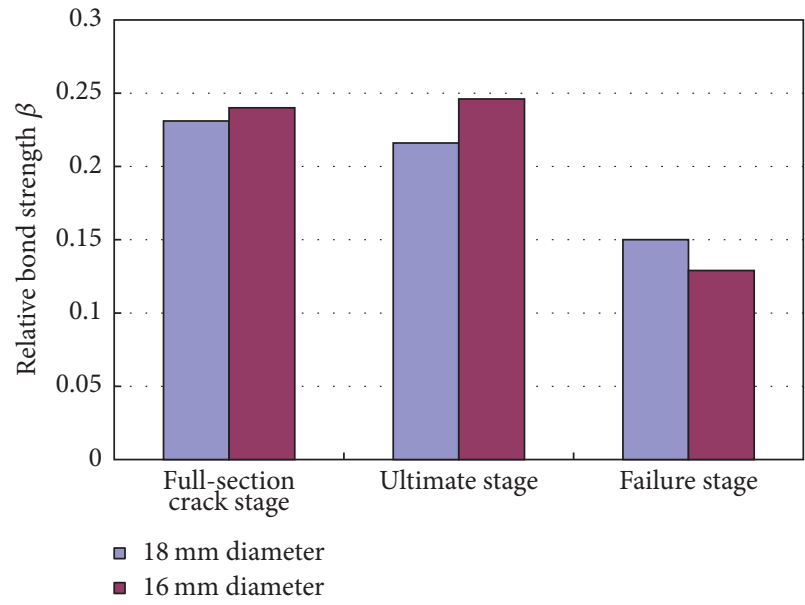

(a) Relative bond strengths with different steel bar diameters

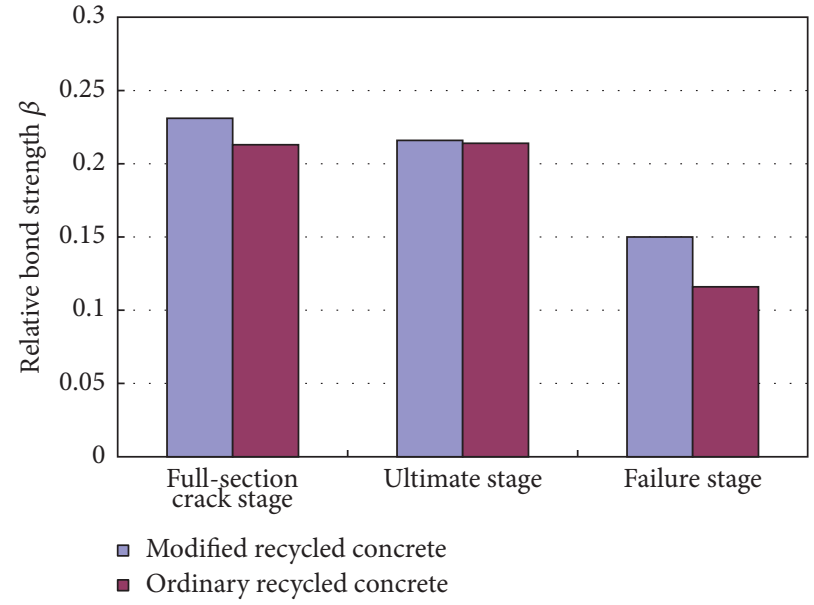

(b) Relative bond strengths of modified and ordinary RAC

FIGURE 11: Relative bond stresses of longitudinal steel bar.

longitudinal steel bar diameter crossing the interior joints of middle column in frame.

(3) Comparing the average bond stress results in each stage of common RAC specimen ZJ3 to that of modified RAC specimen ZJ1, the relative longitudinal steel bar bond strength of ZJ1 is 1.085 times of that of $\mathrm{ZJ} 3$, and the ultimate relative bond strength of ZJ1 is 1.010 times of that of ZJ3.

(4) By adding mineral fly ash in common RAC, the mineral fly ash can directly fill the interface pores of 


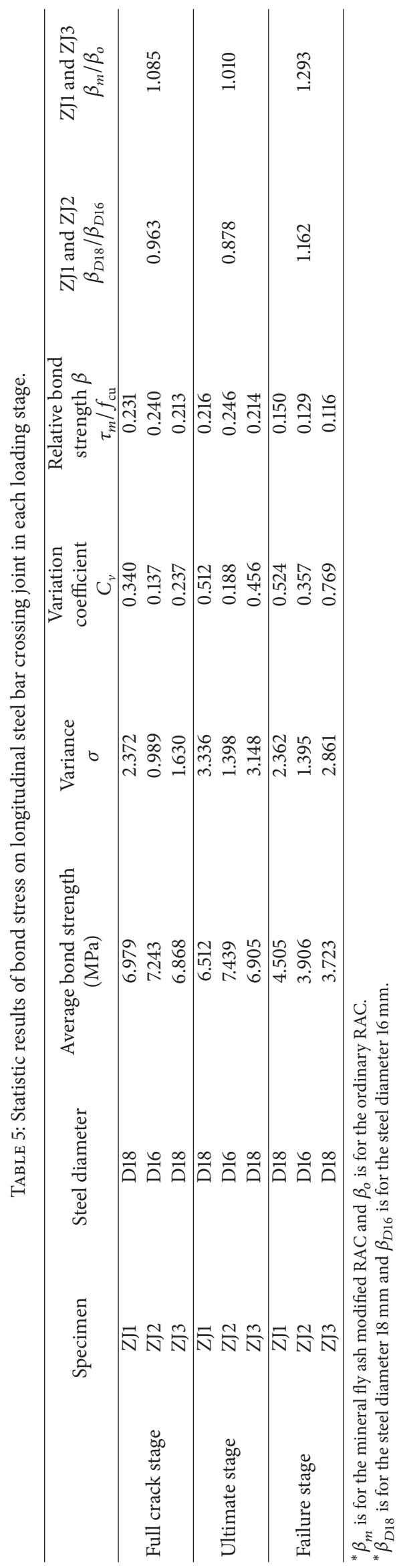


recycled aggregate, bond microcracks, and improve the interface compactness and bonding reaction, as a result improving the bond and friction between steel bars and concrete.

(5) In the full crack stage, the portion of cementing force and frictional force in bond strength is large. And also, in this stage, the bond stress of mineral fly ash modified RAC is increased by $8.5 \%$ of ordinary RAC bond stress.

(6) In the ultimate stage, the bond strength of the longitudinal steel bar mainly depends on the mechanical bite force, and the using of mineral fly ash can increase the bond stress by $1.0 \%$ of ordinary RAC bond stress.

\section{Conclusions}

The distribution law of the bond stress on longitudinal steel bar crossing joint core area was discussed, and the following conclusions were obtained:

(1) The tests indicated that the bearing capacity, failure mode, and seismic performance of the modified recycled concrete interior joint with fly ash equivalent replacement rate of $15 \%$ had few differences from those of conventional recycled concrete. The brittleness in the core area of the RAC concrete specimens with fly ash is slightly more obvious than that of RAC concrete, and the ductility is slightly less than that one.

(2) The mineral fly ash added in RAC can directly fill the interface pores of recycled aggregate, bond microcracks, and can enhance the interface compactness and bonding reaction and as a result improves the bond and friction between steel bars and concrete. In the full crack stage, the bond stress of mineral fly ash modified RAC is increased by $8.5 \%$ of the ordinary RAC bond stress. And, in the ultimate stage, the using of mineral fly ash increases the bond stress by $1.0 \%$ of ordinary RAC bond stress.

(3) The bond stresses of longitudinal steel bars in the full crack stage and the ultimate stage are relatively stable. The average bond strength ranges from 6.512 to $7.439 \mathrm{MPa}$, and the relative bond strength ranges from 0.208 to 0.246 . In the failure stage, the bond strength decreases rapidly. The average bond strength ranges from 3.723 to $4.505 \mathrm{MPa}$, and the relative bond strength ranges from 0.116 to 0.150 . Taking bond strength in full crack stage as the design condition, the bond strength of longitudinal steel bars in RAC can satisfy the requirements of stress transfer, deformation coordination between steel bars and concrete, and safety reserve.

(4) At the same conditions, the relative bond strength in full stage of D18 longitudinal steel bar is $96.3 \%$ of D16 longitudinal steel bar relative bond strength and the relative bond strength ratio is $87.8 \%$, indicating that the larger the steel bar diameter is, the more serious the strength loss is, showing the same influence in ordinary concrete structure. It is suggested that when satisfying design requirements, the diameter of steel bar crossing the interior joint of middle column in frame should be small.

(5) A compression steel stress hysteresis phenomenon existed in the experiment. When the compression steel stress hysteresis phenomenon occurred, the concrete compressive strain in beam end section reached its failure value, while the steel compression strain value was far more less than that of the corresponding compressive strain value according to the section assumption, indicating that the compressive steel cannot be fully exerted. The reason for this stress hysteresis is that the bond stress between the concrete and the steel bar is not enough so that the tension and compression stress on one longitudinal bar can not be transformed in the length of the reinforcement crossing the core area of the joint.

(6) In this experiment, the dense stirrups at the beam end were confined and axial pressure was applied on the columns, which would improve the bond performance of the longitudinal steel bars crossing joints. Because of the limited number of specimens, the considered parameters relating to bond properties are also limited. So the further studies should consider those research deficiencies above.

\section{Conflicts of Interest}

The authors declare that they have no conflicts of interest.

\section{Acknowledgments}

This work was financially supported by Science and Technology Project of Housing and Urban-Rural Development of China (Grant 2013-K4-46) and Higher Education Promotion Project of Anhui Province, China (Grant TSKJ2015B05).

\section{References}

[1] T. C. Hansen and H. Narud, "Strength of recycled concrete made from crushed concrete coarse aggregate," Concrete International, vol. 5, no. 1, pp. 79-83, 1983.

[2] M. Tavakoli and P. Soroushian, "Strengths of recycled aggregate concrete made using field-demolished concrete as aggregate," ACI Materials Journal, vol. 93, no. 2, pp. 182-190, 1996.

[3] R. Sri Ravindrajah, Y. H. Loo, and C. T. Tam, "Strength evaluation of recycled-aggregate concrete by in-situ tests," Materials and Structures, vol. 21, no. 4, pp. 289-295, 1988.

[4] J. Z. Xiao, J. B. Li, Z. P. Sun, and X. M. Hao, "Study on compressive strength of recycled aggregate concrete," Journal of Tongji University (Natural Science Edition), vol. 32, no. 12, pp. 15581561, 2004 (Chinese).

[5] G.-F. Peng, Y.-Z. Huang, H.-S. Wang, J.-F. Zhang, and Q.-B. Liu, "Mechanical properties of recycled aggregate concrete at low and high water/binder ratios," Advances in Materials Science and Engineering, vol. 2013, Article ID 842929, 6 pages, 2013. 
[6] J. Z. Xiao and Y. Lan, "Investigation on the tensile behavior of recycled aggregate concrete," Journal of Building Materials, vol. 9, no. 2, pp. 154-158, 2006 (Chinese).

[7] X. Teng, Y. B. Lu, X. Chen, S. S. Yu, and X. Q. Jiang, "Tests for dynamic tensile of recycled aggregate concrete," Journal of Vibration and Shock, vol. 35, no. 9, pp. 43-51, 2016 (Chinese).

[8] Q. Hu, C. Song, and C. Y. Zou, "Experimental research on the mechanical properties of recycled concrete," Journal of Harbin Institute of Technology, vol. 41, no. 4, pp. 33-36, 2009 (Chinese).

[9] Z. H. Duan, S. C. Kou, and C. S. Poon, "Using artificial neural networks for predicting the elastic modulus of recycled aggregate concrete," Construction \& Building Materials, vol. 44, no. 7, pp. 524-532, 2014.

[10] J.Z. Xiao, "Experimental investigation on complete stress-strain curve of recycled concrete under uniaxial loading," Journal of Tongji University, vol. 35, no. 11, pp. 1445-1454, 2007 (Chinese).

[11] G.-F. Belén, M.-A. Fernando, and C. L. Diego, "Stress-strain relationship in axial compression for concrete using recycled saturated coarse aggregate," Construction \& Building Materials, vol. 25, no. 5, pp. 2335-2342, 2011.

[12] T. Du, W. Wang, Z. Liu, H. Lin, and T. Guo, "The complete stress-strain curve of recycled aggregate concrete under uniaxial compression loading," Journal Wuhan University of Technology, Materials Science Edition, vol. 25, no. 5, pp. 862-867, 2010 (Chinese).

[13] F. T. Olorunsogo and N. Padayachee, "Performance of recycled aggregate concrete monitored by durability indexes," Cement \& Concrete Research, vol. 32, no. 2, pp. 179-185, 2002.

[14] A. Gokce, S. Nagataki, and T. Saeki, "Freezing and thawing resistance of air entrained concrete incorporating recycled coarse aggregate: the role of air content in demolished concrete," Cement \& Concrete Research, vol. 34, no. 5, pp. 799-806, 2004.

[15] J. S. Ryu, "An experimental study on the effect of recycled aggregate on concrete properties," Magazine of Concrete Research, vol. 54, no. 1, pp. 7-12, 2002.

[16] V. W. Y. Tam, X. F. Gao, and C. M. Tam, "Microstructural analysis of recycled concrete produced from two-stage mixing approach," Cement \& Concrete Research, vol. 35, no. 6, pp. 11951203, 2005.

[17] G. F. Belen and M. A. Fernando, "Shear strength of recycled concrete beams," Construction \& Building Materials, vol. 21, no. 4, pp. 887-893, 2007.

[18] G. F. Belén, M. A. Fernando, and M. L. Isabel, "Structural shear behaviour of recycled concrete with silica fume," Construction \& Building Materials, vol. 23, no. 11, pp. 3406-3410, 2009.

[19] W. C. Choi and H. D. Yun, "Long-term deflection and flexural behaviour of reinforced concrete beams with recycled aggregate," Materials \& Design, vol. 51, no. 5, pp. 742-750, 2013.

[20] M. Arezoumandi, J. S. Volz, and K. H. Khayat, "An experimental study on shear strength of reinforced concrete beams with $100 \%$ recycled concrete aggregate," Construction \& Building Materials, vol. 88, no. 2, pp. 612-620, 2015.

[21] Y.-F. Yang and L.-H. Han, "Experimental behaviour of recycled aggregate concrete filled steel tubular columns," Journal of Constructional Steel Research, vol. 62, no. 12, pp. 1310-1324, 2006.

[22] W.-C. Choi and H.-D. Yun, "Compressive behavior of reinforced concrete columns with recycled aggregate under uniaxial loading," Engineering Structures, vol. 41, pp. 285-293, 2012.

[23] Y.-F. Yang and G.-L. Ma, "Experimental behaviour of recycled aggregate concrete filled stainless steel tube stub columns and beams," Thin-Walled Structures, vol. 66, pp. 62-75, 2013.
[24] J. Xiao, Y. Huang, and Z. Sun, "Seismic behavior of recycled aggregate concrete filled steel and glass fiber reinforced plastic tube columns," Advances in Structural Engineering, vol. 17, no. 5, pp. 693-707, 2014.

[25] V. Corinaldesi, V. Letelier, and G. Moriconi, "Behaviour of beam-column joints made of recycled-aggregate concrete under cyclic loading," Construction \& Building Materials, vol. 25, no. 4, pp. 1877-1882, 2011.

[26] B. K. Liu, L. H. Chen, A. Zhou, Y. Zeng, and L. Fu, "Experimental study on seismic behavior of recycled aggregate concrete beam-column interior-joints," Journal of Building Structures, vol. 32, no. 11, pp. 109-115, 2011 (Chinese).

[27] V. C. Letelier Gonzalez and G. Moriconi, "The influence of recycled concrete aggregates on the behavior of beam-column joints under cyclic loading," Engineering Structures, vol. 60, pp. 148-154, 2014.

[28] J. Zhang, W. Cao, S. Meng, C. Yu, and H. Dong, "Shaking table experimental study of recycled concrete frame-shear wall structures," Earthquake Engineering and Engineering Vibration, vol. 13, no. 2, pp. 257-267, 2014 (Chinese).

[29] J. Xiao, Y. Sun, and H. Falkner, "Seismic performance of frame structures with recycled aggregate concrete," Engineering Structures, vol. 28, no. 1, pp. 1-8, 2006.

[30] L. Butler, J. S. West, and S. L. Tighe, "The effect of recycled concrete aggregate properties on the bond strength between RCA concrete and steel reinforcement," Cement \& Concrete Research, vol. 41, no. 10, pp. 1037-1049, 2011.

[31] B. Wang, G. L. Bai, H. J. Dai, and S. H. Wu, "Experimental and mechanical analysis of bond-slip performance between recycled concrete and rebar," Engineering Mechanics, vol. 30, no. 10, pp. 54-64, 2013 (Chinese).

[32] Q. Hu, W. W. Chen, and C. Y. Zhou, "Experimental study on bonding properties of recycled concrete," Journal of Harbin Institute of Technology, vol. 42, no. 12, pp. 1849-1854, 2010 (Chinese).

[33] J. Z. Xiao and B. Lei, "Experimental study on bond behavior between corroded steel bars and recycled concrete," Journal of Building Structures, vol. 32, no. 1, pp. 58-62, 2011 (Chinese).

[34] M. Guerra, F. Ceia, J. D. Brito, and E. Júlio, "Anchorage of steel rebars to recycled aggregates concrete," Construction \& Building Materials, vol. 72, pp. 113-123, 2014.

[35] W. X. Zhu and B. K. Liu, "Experimental study of the bond behavior of eccentric beam-column joints under cyclic reverse loading," Journal of Hefei University of Technology, vol. 26, no. 5, pp. 966-970, 2003 (Chinese).

[36] J. R. Tang, Seismic Resistance of Joints in Reinforced Concrete Frames, Southeast University Press, Nanjing, China, 1989 (Chinese). 

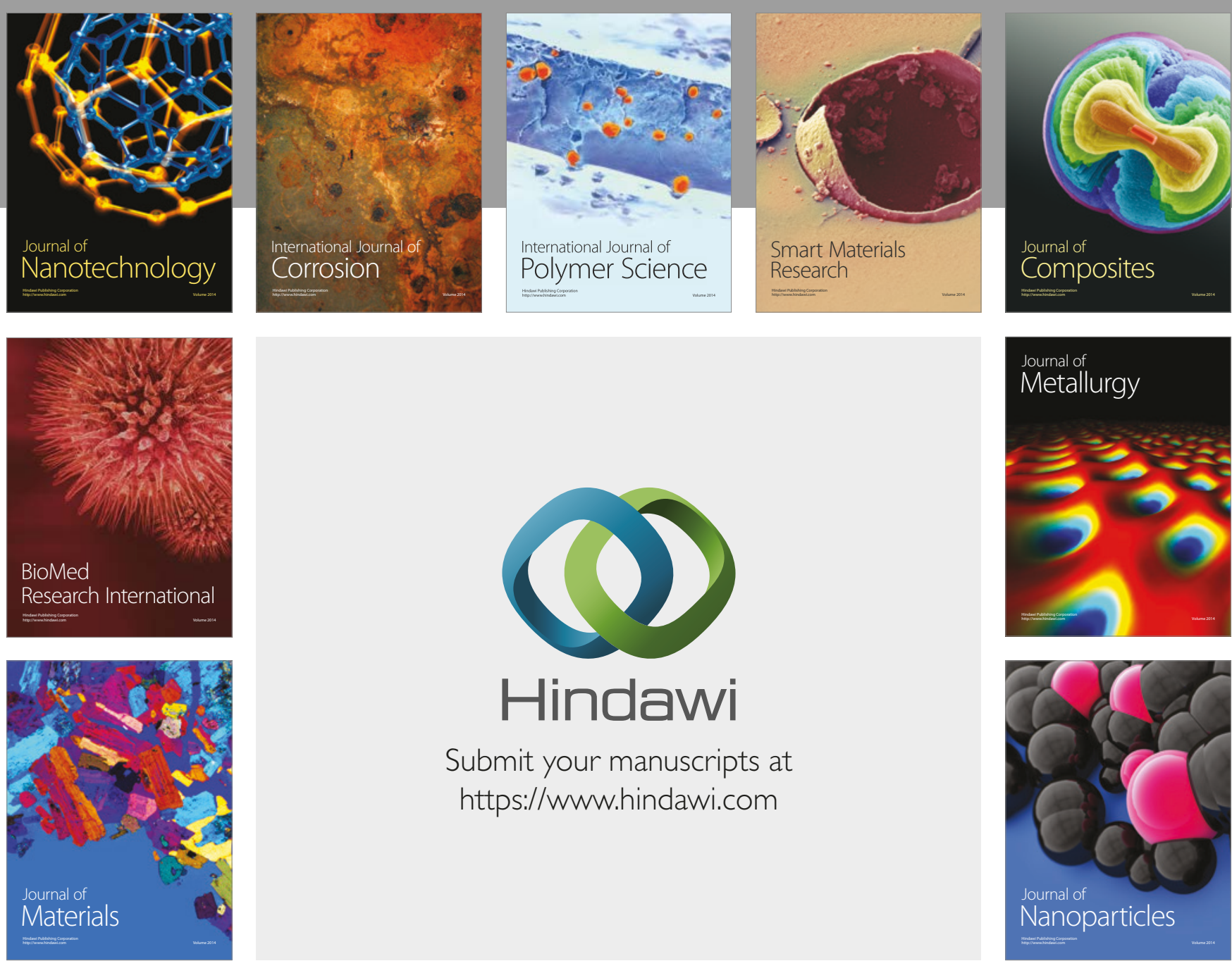

\section{Hindawi}

Submit your manuscripts at

https://www.hindawi.com
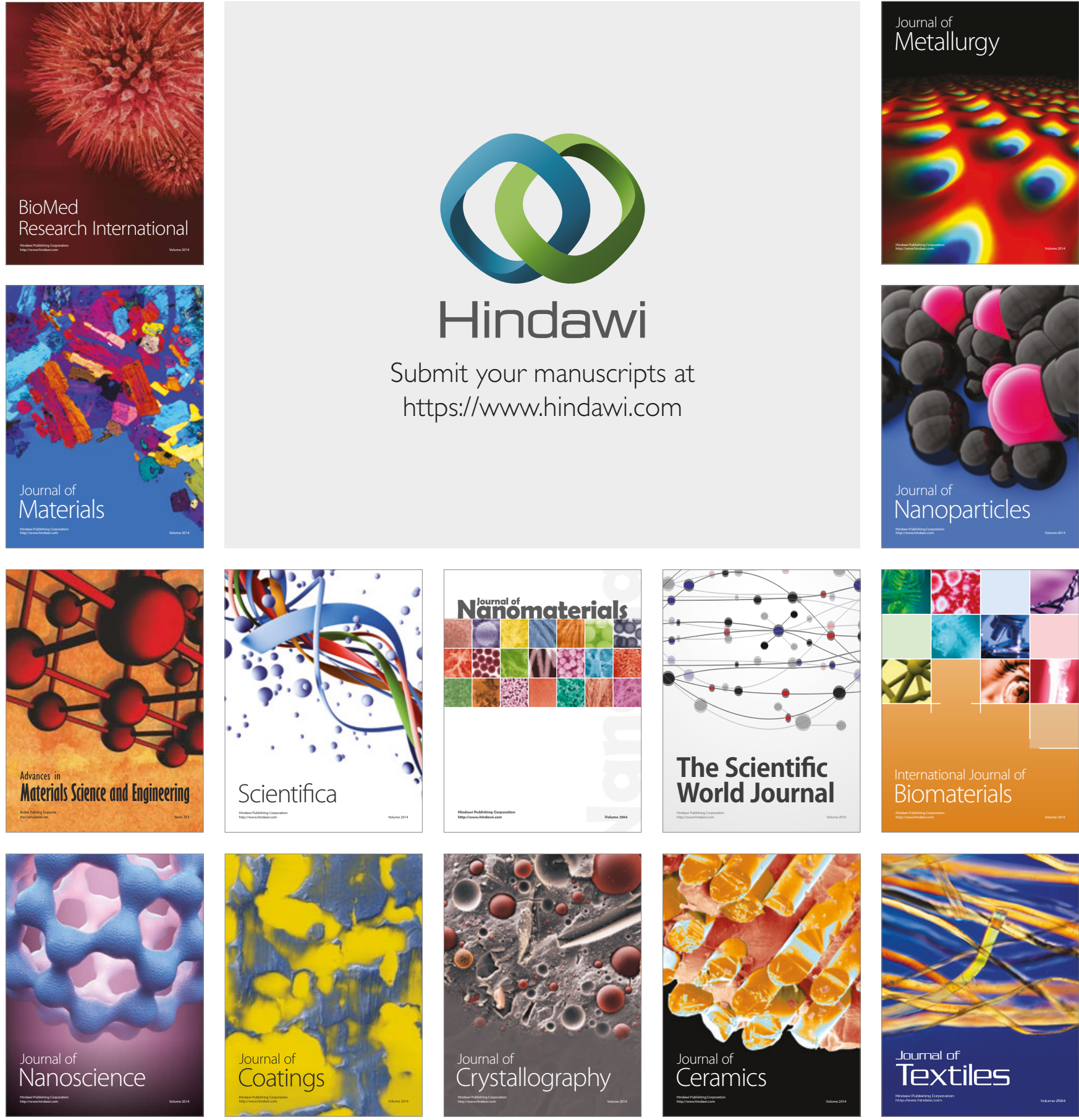

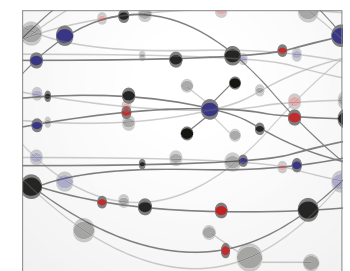

The Scientific World Journal
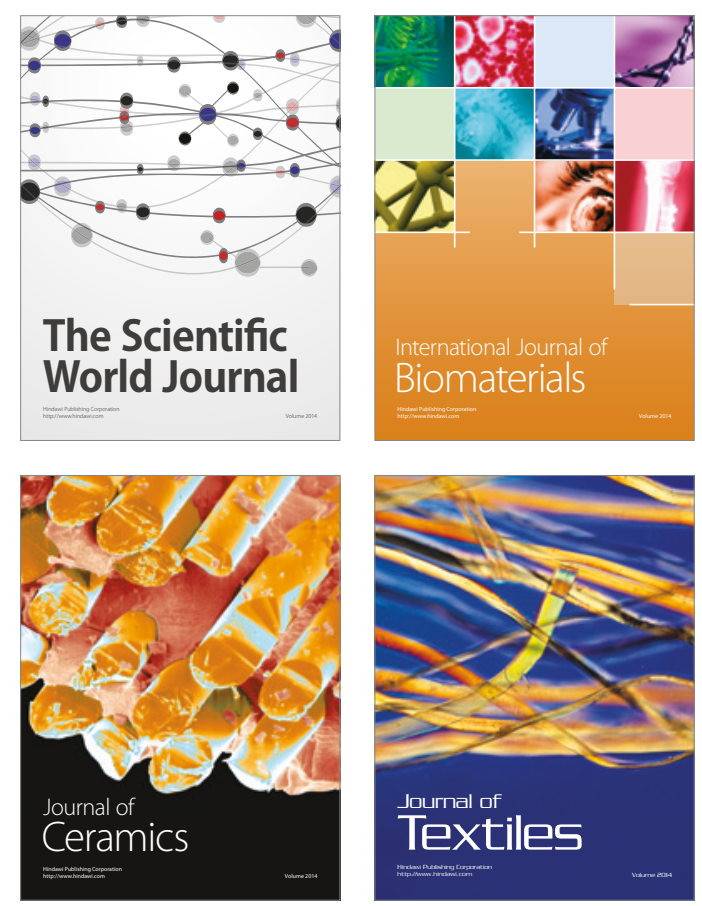